\title{
ISOLAMENTO E CARACTERIZAÇÃO DO POLÍMERO NATURAL EXTRAÍDO DO CACTO MELOCACTUS ZEHNTNERI (COROA DE FRADE) E SUA APLICAÇÃO COMO COAGULANTE/FLOCULANTE NO TRATAMENTO DE ÁGUA
}

\author{
SANTOS, M. S. S. N. *(IFRN) ; VIEIRA, M. N. (IFRN) ; VIEIRA, M. G. S. (IFCE)
}

\section{RESUMO}

Mesmo tendo sua eficácia comprovada, os coagulantes químicos utilizados no tratamento de água, apresentam algumas desvantagens, tais como: a ineficácia em baixa temperatura da água, os custos de aquisição altos, a produção de grande quantidade de lodo, ação significativa sobre o $\mathrm{pH}$ da água tratada $\mathrm{e}$ efeitos prejudiciais sobre a saúde humana, como indícios do alumínio está ligado ao desenvolvimento do Mal de Alzheimer. Por isso, ultimamente têm-se crescido as pesquisas relacionadas aos coagulantes de origem natural, que poderiam ser usados como coagulantes primários ou auxiliares. $\mathrm{O}$ uso de polímeros naturais no tratamento de água é um campo promissor, devido as vantagens associadas a sua aplicação. Dessa forma, esse trabalho objetiva isolar e caracterizar o polímero natural extraído do cacto Coroa de frade (Melocactus zehntneri) e avaliar o seu desempenho no processo de coagulação/floculação no tratamento de água. 0 Melocactus Zehntneri é um cacto comum na caatinga, com maior facilidade de ser encontrado na região do Seridó do Rio Grande do Norte.

PALAVRAS-CHAVE: Extrato de cacto. Caracterização do polímero. Tratamento de água. Coagulação/Floculação.

\section{ISOLATION AND CHARACTERIZATION OF NATURAL POLYMER EXTRACTED FROM CACTU MELOCACTUS ZEHNTNERI (COROA DE FRADE) AND ITS APPLICATION AS A COAGULAT/FLOCULANT IN WATER TREATMENT}

\begin{abstract}
Even with their proven effectiveness, chemical coagulants used in water treatment have some disadvantages, for example: inefficiency in water under low temperature, high purchase costs, large amount of sludge production, significant action on the $\mathrm{pH}$ of the treated water and harmful effects on human health, such as aluminum signs, linked to the development of Alzheimer's disease. Therefore, lately it has been increased research relating to clotting of natural origin, which could be used as primary or auxiliary coagulants.

The use of natural polymers for water treatment is a promising field, due to advantages, associated with their application. Thus, this study aims to isolate and to characterize the natural polymer isolated from Cactus "Coroa de Frade" (Melocactus zehntneri) and to evaluate its performance in the process of coagulation/flocculation in water treatment. Melocactus zehntneri is a common cactus found in the savanna, this plant is more easily found in the Seridó region, part of the Rio Grande do Norte.
\end{abstract}

KEY-WORDS: CACTUS EXTRACT. POLYMER CHARACTERIZATION. WATER TREATMENT. COAGULATION/

FLOCCULATION 


\section{ISOLAMENTO E CARACTERIZAÇÃO DO POLÍMERO NATURAL EXTRAÍDO DO CACTO MELOCACTUS ZEHNTNERI (COROA DE FRADE) E SUA APLICAÇÃO COMO COAGULANTE/FLOCULANTE NO TRATAMENTO DE ÁGUA}

\section{INTRODUÇÃO}

A água é um recurso vital e indispensável que faz parte da identidade dos ambientes, paisagens, ecossistemas e da vida humana. Sabe-se que sua ocupação é de $75 \%$ da superfície da terra e é o constituinte inorgânico mais abundante na matéria viva (LIBÂNIO apud ZARA, 2012).

Mesmo com tamanha importância, é frequente o seu mau uso, o que ocasiona redução na disponibilidade de água doce e limpa, bem como, a presença de substâncias, micro-organismos e elementos químicos, nocivos à saúde humana.

É estimado que em alguns países em desenvolvimento, há várias doenças que provêm da baixa qualidade da água fornecida para o consumo. É o caso do Brasil, onde aproximadamente $60 \%$ das doenças enfrentadas por sua população estão relacionadas ao saneamento básico ineficiente (DI BERNARDO; CENTURIONE FILHO; ZARA 2012).

Dessa forma, para evitar tantos danos, é necessário que a água passe por um tratamento eficiente antes de ser consumida, chegando às nossas torneiras com uma boa qualidade para o consumo. Esse processo consiste em uma série de operações unitárias, dentre as quais se destaca a coagulação, um processo no qual se utiliza produtos químicos com o intuito de reduzir ou eliminar composto presentes na água (RICHTER apud ZARA, 2012).

Para ser usado no tratamento de água, o coagulante - geralmente sulfato de alumínio - precisa formar na água cátions metálios ligados com o oxigênio, liberando íons $\mathrm{H}^{+}$. Assim, obtêm um precipitado, que na mistura rápida entram em contato com as impurezas em suspensão, desestabilizando-as. Com a posterior colisão destas partículas ocorre a floculação (LIBÂNIO apud LENZ , 2011).

"O sulfato de alumínio é o coagulante químico com grande disponibilidade, sendo o mais empregado em estações de tratamento de água brasileiras, e apresenta baixo custo. Ao ser adicionado a água, quase instantaneamente e de modo complexo, ocorrem reações de polimerização e hidrólise, que se combinam e formam espécies polinucleares de alumínio que são responsáveis por promover a desestabilização dos coloides" (LIBÂNIO, 2008 apud ZARA, 2011; p. 76).

Zara (2011) ainda afirma que, mesmo tendo sua eficácia comprovada, os coagulantes químicos utilizados no tratamento de água, apresentam algumas desvantagens, tais como: a ineficácia em baixa temperatura da água, os custos de aquisição altos, a produção de grande quantidade de lodo, ação significativa sobre o pH da água tratada e efeitos prejudiciais sobre a saúde humana, como indícios do alumínio está ligado ao desenvolvimento do Mal de Alzheimer. 
Por isso, ultimamente têm-se crescido as pesquisas relacionadas aos coagulantes de origem natural, que poderiam ser usados como coagulantes primários ou auxiliares. Eles são reconhecidos por apresentarem bons resultados e por oferecerem também algumas vantagens, como a desidratação do lodo gerado, bem como, acréscimo no tamanho, na densidade e na resistência da matéria floculada. Além disso, aumentam a produção de água tratada e a redução da dimensão de unidades de floculação e decantação em uma Estação de Tratamento de Água (ETA) (LIBÂNEO, 2008 apud ZARA, 2011).

Estudos recentes, que vêm ganhando espaço, avaliam a utilização de polímeros naturais extraídos de cactos. De acordo com Zhang et al. (2006), "cactáceos têm recebido grande atenção nos últimos anos devido à sua composição química e estrutural, de componentes nutritivos e médicos, como proteínas, amilose, ácido málico, resina, vitaminas e celulose".

"Diaz et al. (1999), utilizando o cacto Latifariae e a Prosopisjuliflora como coagulantes, forneceu água decantada com valores de turbidez abaixo de 10 UNT. Zhang et al. (2005) fez uso de polímero obtido do cacto Opuntia como auxiliar de coagulação ao cloreto de alumínio, obtendo turbidez remanescente abaixo de 5 UNT, superior ao obtido apenas com o cloreto de alumínio como coagulante primário" (LENZ, et al., p.02).

Com base nesses resultados, é notório que a utilização de polímeros naturais extraídos de cactos é promissora, embora seja ainda limitada à escala laboratorial.

$\mathrm{Na}$ tentativa de obter um melhor resultado na aplicação desses coagulantes naturais, este trabalho tem por objetivo isolar/purificar o polímero extraído do cacto Melocactus Zehntneri (coroa de frade) - retirando suas impurezas mais frequentes, tais como, os sais inorgânicos e outras substâncias de baixa massa molar, além de proteínas, ligninas e ácidos nucléicos - e assim utiliza-lo diretamente como auxiliar nos processos de coagulação/ floculação no tratamento de água.

O Melocactus Zehntneri (coroa de frade) é um cacto comum na caatinga, com maior facilidade de ser encontrado na região do Seridó do Rio Grande do Norte. É caracterizado pelo seu cefálio (espécie de coroa em tom vermelho). Também utilizada para fins medicinais, alimentares e decorativos (CERRATINGA, 2015 apud MELO, 2015).

\section{MATERIAIS E MÉTODOS}

\section{Extração do polímero natural}

O cacto Melocactus Zehntneri (coroa de frade) será coletado no município de Currais Novos, Rio Grande do Norte. Será limpo, cortado, macerado, e o polímero extraído utilizando-se duas metodologias: com solução de cloreto de sódio $1 \%(\mathrm{~m} / \mathrm{v})$ e com ácido clorídrico 0,01 mol. $\mathrm{L}^{-1}$, ambas sob agitação. A dispersão resultante será filtrada e o extrato reservado em geladeira.

4a Semana de Química - IFRN, 2016 


\section{Precipitação e caracterização do polímero}

Utilizando-se os diferentes extratos obtidos do cacto, o extrato com $\mathrm{HCl}$ e o com $\mathrm{NaCl}$, será realizada a precipitação do polímero, possivelmente, polissacarídeos. Primeiramente, será realizada uma tentativa de precipitação alcoolica. Caso, não haja precipitação utilizando-se o etanol, outras tentativas serão realizadas utilizando-se, por exemplo, $\mathrm{NaCl}$ ou acetona. Para a precipitação alcoolica, inicialmente, será ajustado o pH dos extratos para aproximadamente 7,0. Logo após, será adicionado etanol, na proporção extrato:álcool de 1:4 (v/v). Se houver precipitação do polímero, as dispersões serão filtradas, e o polímero retido no filtro será lavado com álcool para retirada de impurezas. Uma vez isolado, o polímero seco será caracterizado, inicialmente utilizando-se a técnica de espectroscopia de absorção na região do infravermelho (FTIR). Outras técnicas poderão ser usadas, tais como Cromatografia de Permeação em Gel (GPC), Ressonância Magnética Nuclear de Hidrogênio (RMN), Análise termogravimétrica (TGA), Reologia dinâmica e Análise elementar. Todas as análises serão realizadas no Laboratório de Polímeros (LabPol), na Universidade Federal do Ceará (UFC).

\section{Preparo da água utilizada}

A água sintética que será utilizada nos testes de remoção de turbidez será produzida de acordo com os procedimentos utilizados por Diaz et al (1999) com a seguinte composição química: $32,85 \mathrm{mg} . \mathrm{L}^{-1}$ de $\mathrm{KCl} ; 125,70 \mathrm{mg} \cdot \mathrm{L}^{-1}$ de $\mathrm{NaHCO}_{3} ; 40,00 \mathrm{mg} . \mathrm{L}^{-1}$ de $\mathrm{MgCl} \cdot 6 \mathrm{H}_{2} \mathrm{O} ; 75,70 \mathrm{mg} \cdot \mathrm{L}^{-1}$ de $\mathrm{CaCO}_{3}$.

Após o preparo, a água será submetida a análises e caracterizações físicoquímicas, que consiste na determinação do $\mathrm{pH}$, turbidez e alcalinidade.

\section{Determinação do pH da água}

$\mathrm{O}$ pH será determinado através do uso do pH-metro (Digimed - Modelo DM-22). Será verificado o pH da água antes e após aplicações dos coagulantes.

\section{Determinação do nível de turbidez}

Para a análise de turbidez da água, será utilizado o turbidímetro (Modelo Q279P), onde as análises de turbidez das amostras serão realizadas antes da aplicação do polímero na água e após o processo de coagulação/floculação.

\section{Determinação da alcalinidade}

Será realizado pelo método da titulação visual, de acordo com a seguinte metodologia: em um erlenmeyer, à uma amostra de $100 \mathrm{~mL}$ da água será adicionada 10 gotas de solução alcoólica de fenolftaleína. A amostra será titulada com solução de ácido sulfúrico 0,005 mol. $\mathrm{L}^{-1}$ até o desaparecimento da coloração rósea e o volume de ácido gasto será anotado. Em seguida, será adicionada 4 gotas de solução de alaranjado de 
metila, e será realizada a titulação com a solução de ácido sulfúrico 0,004 mol. $\mathrm{L}^{-1}$, até se observar a viragem do indicador de amarelo para alaranjado.

\section{Aplicação do polímero natural purificado}

O extrato obtido do cacto e o polímero isolado/purificado irão ser aplicados na água sintética, bem como, na água disponibilizada para o consumo distribuída na cidade de Currais Novos - RN. Dessa forma, será possível avaliar o desempenho de ambos matérias como coagulantes/floculantes.

\section{RESULTADOS ESPERADOS}

Essa pesquisa permitirá avaliar o desempenho como coagulante/floculante de dois matérias diferentes, visando aplicação no tratamento de água. O primeiro, é um extrato obtido do cacto "Coroa de frade". Esse material é facilmente obtido e será usado sem nenhum tratamento prévio. A partir do extrato, será realizado procedimentos para isolar/purificar o polímero presente no cacto, possivelmente polissacarídeos. Também espera-se caracterizar o polímero. Ambos materiais serão testados como coagulante/floculante e a partir dos resultados obtidos será possível comparar o desempenho dos materiais, bem como, avaliar se é viável a aplicação do polímero puro.

\section{REFERÊNCIAS}

LENZI, E.; FAVERO, E.; LUCHESE, E. B. Introdução à química da água: ciência, vida e sobrevivência. Rio de Janeiro: LTC, 2009.

MELO, R. K.; Uso do cacto melocactus zehntneri (coroa de frade) como fonte de polímeros utilizados para a diminuição de turbidez da água. Currais Novos, 2015.

LIBÂNIO, Marcelo. Fundamentos de qualidade e tratamento de água. 3. ed. Campinas, SP: Átomo, 2010.

ZARA, R. F.; THOMAZINI M. H.; LENZ G. F. Estudo da eficiência de polímero natural extraído do cacto mandacaru (Cereus jamacaru) como auxiliar nos processos de coagulação e floculação no tratamento de água." Revista de estudos ambientais 14.2 (2012): 75-83.

ZHANG, J. et al. A preliminary study on cactus as coagulant in water treatment. Bioprocess Chemistry, v. 41, p. 730-733, 2006.Disponível em:

http://site.sabesp.com.br/site/interna/Default.aspx?secaold=40. Acesso em: 25 nov. 2015. 